Distribution of this document is unlimited.

\title{
THE EFFECTS OF ENVIRONMENTAL TEMPERATURE CHANGES ON THE EKG OF THE \\ SQUIRREL MONKEY (SAIMIRI SCIUREUS)
}

\author{
Arnold Eskin and David C. Riccio
}
Bureau of Medicine and Surgery
Project MR005. 13-9010
Subtask 5 Report No. 2
NASA Order No. R-39

\author{
Approved by \\ Captain A. Graybiel, MC, USN \\ Director of Research
}

Released by

Captain H. C. Hunley, MC, USN Commanding Officer

\section{May 1965}

*This research was conducted under the sponsorship of the Office of Life Science Programs, National Aeronautics and Space Administration.

U. S. NAVAL SCHOOL OF AVIATION MEDICINE

U. S. NAVAL AVIATION MEDICAL CENTER PENSACOLA, FLORIDA 


\section{SUMMARY PAGE}

\section{THE PROBLEM}

To investigate the effects of environmental temperature changes on the heart rate and T-wave amplitude of squirrel monkeys (Saimiri sciureus).

\section{FINDINGS}

Electrocardiograms of four monkeys were recorded during exposure of the animals to air slowly heated $5^{\circ}-8^{\circ} \mathrm{C}$ above room level. Neither rectal nor skin temperature was affected. Deceleration of the heart and increase in T-wave amplitude under these conditions are noteworthy phenomena. As a control, EKG records for two of the monkeys were similarly recorded during exposure to slowly cooling air. Rectal temperature showed a very small change. Heart rate and respiration rate increased and T-wave amplitude decreased considerably.

\section{ACKNOWLEDGEMENTS}

We wish to thank $\mathrm{Dr}$. Dietrich Beischer for his continuing, support and encouragement throughout the study; James Knepton for providing several monkeys adapted to restraint; John Nackley and William Miller for yeoman service in running the animals and the tedious analysis of data; John S. Thach, Jr. and Al Thorsen for providing and modifying much of the apparatus, respectively; Jerry Sentura for advice and criticism of the manuscript; and Beth Boss and Dorothy Riccio for their long enduring patience in translating our handwriting. 


\section{INTRODUCTION}

The maintenance of body temperature about a fixed point within a wide range of en-

vironmental temperatures is a defining characteristic of homeotherms. A number of studies has shown that when the limits are exceeded and the body temperature modified, marked changes occur in the heart rate (1). Less attention has been given to the response during small ambient temperature changes when body temperature is still regulated within the homeostatic range. Adult men exposed to warm environments are reported to show increased heart rates although the ir body temperatures remained normal $(9,17)$. However, comparative data on cardiac responses in primates during environmental temperature changes are lacking.

Values for normal heart rates, body temperatures, and respiration rates of squirrel monkeys have recently been published (2). While it has been reported that the heart rate of the squirrel monkey provides a sensitive index of the severity of various environments (8), the response of the squirrel monkey to changes in ambient temperature has not been described. Due to the increasing use of the parameters of the squirrel monkey's electrocardiogram (EKG) as an experimental index $(3,8)$, a study was performed to determine the effect of an environmental air temperature change on the EKG of squirrel monkeys while their body temperature remained constant.

\section{APPARATUS AND PROCEDURE}

Two male and two female adult squirrel monkeys (Saimiri sciureus), weighing between 450 and 500 grams, served as subjects. Except for test sessions, the animals were housed in the U.S. Naval School of Aviation Medicine colony. Cage room temperature was maintained at $78^{\circ}-81^{\circ} \mathrm{F}$. The monkeys were adapted to restraint by using slowly increased periods of immobilization for several weeks. At the time of the experiments all monkeys were accustomed to seven hours of continuous restraint. The restraint consisted of a fitted, half-cylindrical couch providing ample ventilation into which the monkey was placed on its back. The unanesthetized animal was fixed in place by a series of Velcro (Amer. Velcro, Inc.) strips across the front of the restrainer.

A Sanborn Cardiette was used to monitor the EKG. Two small disc-shaped electrodes, 9 millimeters in diameter, were taped to the left and right sides of the shaved chest. Plastic foam soaked with electrode paste was placed between the electrode and the chest. Gauze was wrapped around the animal to prevent the taped electrodes from slipping. Care was taken not to restrict the monkey's breathing. The restrained animal was maintained in an upright position at all times.

Several different techniques were used to regulate air temperature around the monkey. In the first heating test, the air was warmed by using a flexible asbestos heating belt arranged near the monkey. The monkey was enclosed within a plastic hood with numerous holes for ventilation. In the other heating tests, the animal was placed either in a foil-lined box or in a copper tube of slightly greater diameter than the restrainer. 
There was ample air flow for ventilation through both systems. A heater with a fan and thermostat was placed near the box or tube, and the air around the monkey was warmed by radiation from the sides of the container. The cooling apparatus consisted of a copper cylinder with water coils around it. By regulating the temperature of the water pumped through the coils, the air temperature within the cylinder could be changed appropriately. An air pump provided an ample air flow. Air temperature was monitored by thermistors. Most experiments used two probes, one attached one inch from the back of the restrainer at neck level and the other placed one inch in front of the restrainer at midsection. In the few cases where only one probe was employed, the former location was used. Rectal temperatures were monitored in two cases to insure that the environmental temperatures used did not alter body temperatures. Skin temperature was also monitored by taping a surface probe to the monkey's shaved abdomen.

During the test session, the restrained monkeys were visually isolated from the experimenters. Through a speaker placed about a foot from the monkey's head, a 70-80 db "white" noise was presented to mask extraneous room sounds which might affect heart rate. Preliminary work indicated that baseline heart rate did not stabilize until the monkey had been in the experimental situation for at least an hour. Accordingly, baseline samples were not begun until about $1-1 / 2$ hours after restraining the monkey. Thus, the first hour of baseline or control EKG data represent the third hour of isolated restraint for the monkey. EKG's were recorded for a period of one minute at regular intervals. The temperature increases were between $5^{\circ}-8^{\circ} \mathrm{C}$ over a one to two-hour period. These rather small changes were chosen in order to allow the animal to maintain his normal body temperature. Another test was run in which a monkey was exposed to a $15^{\circ} \mathrm{C}$ rise in ambient temperature in five minutes. In addition, two of the animals employed in the warm exposure were later exposed to a temperature decrease of $8^{\circ}-10^{\circ} \mathrm{C}$ over a similar time period. This procedure provided further information on the temperature continuum, as well as establishing an experimental control on the effects of excitement on the heart rate. A summary of the temperature conditions employed as well as the data obtained is presented in Table I of the RESULTS section.

The EKG's were evaluated to obtain heart rates and T-wave amplitudes for each minute sampled. Heart rate was determined for the first six beats in fifteen three-second cycles. The median of these fifteen samples was taken to represent the heart rate at that point.

$T$-wave amplitudes were determined with respect to the $P-Q$ junction in the baseline. The $T$-wave at the height of the first breathing cycle in each three-second division of the EKG was measured. Fifteen such measurements were made to determine the average Twave amplitude for a one-minute period. Breathing rates were established by measuring the cyclical variation in the height of the $T$-waves. The median of eleven readings was used to represent breathing rate for a one-minute sample. Breathing rates could not be obtained in three of the seven tests due to fluctuating baselines or faint stylus tracings. 


\section{RESULTS}

The effects of small environmental temperature elevation on the cardiac functions and breathing rate are shown in Figures 1,2, and 3. A detailed record of the response of monkey $\mathrm{LI}$ (Figure 1) with respect to time and temperature shows that rectal and skin temperatures remained constant throughout the trial. No systematic change appeared in respiration rate. In contrast, heart rate decreased and T-wave amplitude increased almost immediately with rising environmental temperature. The abrupt and atypical termination of the trial was due to an apparatus failure.

The changes in heart rate and T-wave amplitude with respect to time are shown for monkey MK in Figure 2. The baseline heart rate dropped fairly abruptly during the heating period; however, the minimum heart beat values were reached fifteen to twenty-five minutes after the peak temperature was attained. It is also evident that the posttreatment level was considerably more variable than the pretreatment baseline. The postheating effect may reflect the body's reflex attempt to maintain homeostatic balance in the face of the rapid increase and decrease in air temperature.

The marked correlation between $T$-wave amplitude and ambient temperature elevation is readily seen in data from monkey LZ (Figure 3 ). The sharp changes in T-wave amplitude paralleled air temperature changes but with a nearly constant thirty minute lag. The magnitude of heart rate deceleration was somewhat less than in the other monkey, but was still apparent. During the two-hour baseline heart rate only three points fell below 275 beats/minute. In contrast, during the period of high temperature and for a short time after (during falling temperature), the heart rate dropped to less than 260 beats/minute for nearly one hour. The heart rate returned to the baseline about one hour after the air temperature returned to a normal value.

The physiological responses of monkey $\mathrm{LI}$ to a fall in air temperature are shown in Figure 4. While body temperature remained relatively constant, heart rate rose rapidly, leveled off, and then slowly returned to the baseline as the air temperature returned to $27^{\circ} \mathrm{C}$. T-wave amplitude dropped as the air temperature changed, and the T-wave minimum lagged twenty minutes behind the temperature minimum. Breathing rate followed a pattern similar to heart rate and showed a quick return to baseline values. A small overand under-compensation can be seen in the rectal temperature during the lowered air temperature, indicating temperature regulation by the monkey.

The effects of environmental temperature changes on heart rate and T-wave amplitude for all trials are summarized in Table 1 . The baseline values for heart rate and $T$-wave amplitude represent the medians of six to ten one-minute samples obtained during the constant temperature period. The experimental values represent the median of three to five successive one-minute samples taken five minutes apart during the temperature changes.

The statistical significance of the difference between baseline and experimental heart rates was evaluated by the Mann-Whitney $U$ test. Each animal served as its own control. Thus for the same monkey, the six to ten heart rate values recorded prior to thermal change 


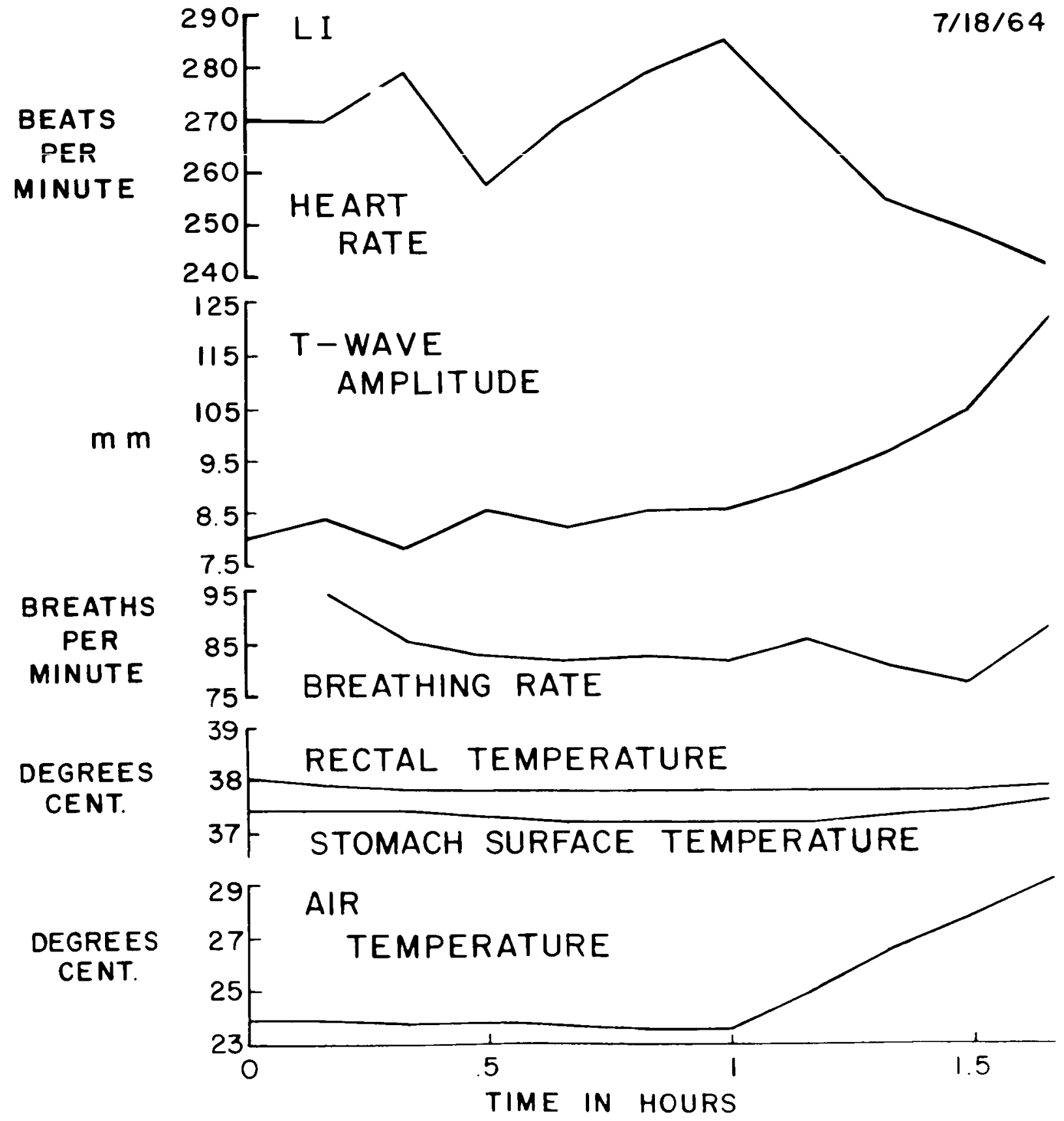

Figure 1

Effects of $5^{\circ} \mathrm{C}$ Rise in Temperature in 45-minutes on Several

Physiological Parameters in Monkey LI. 

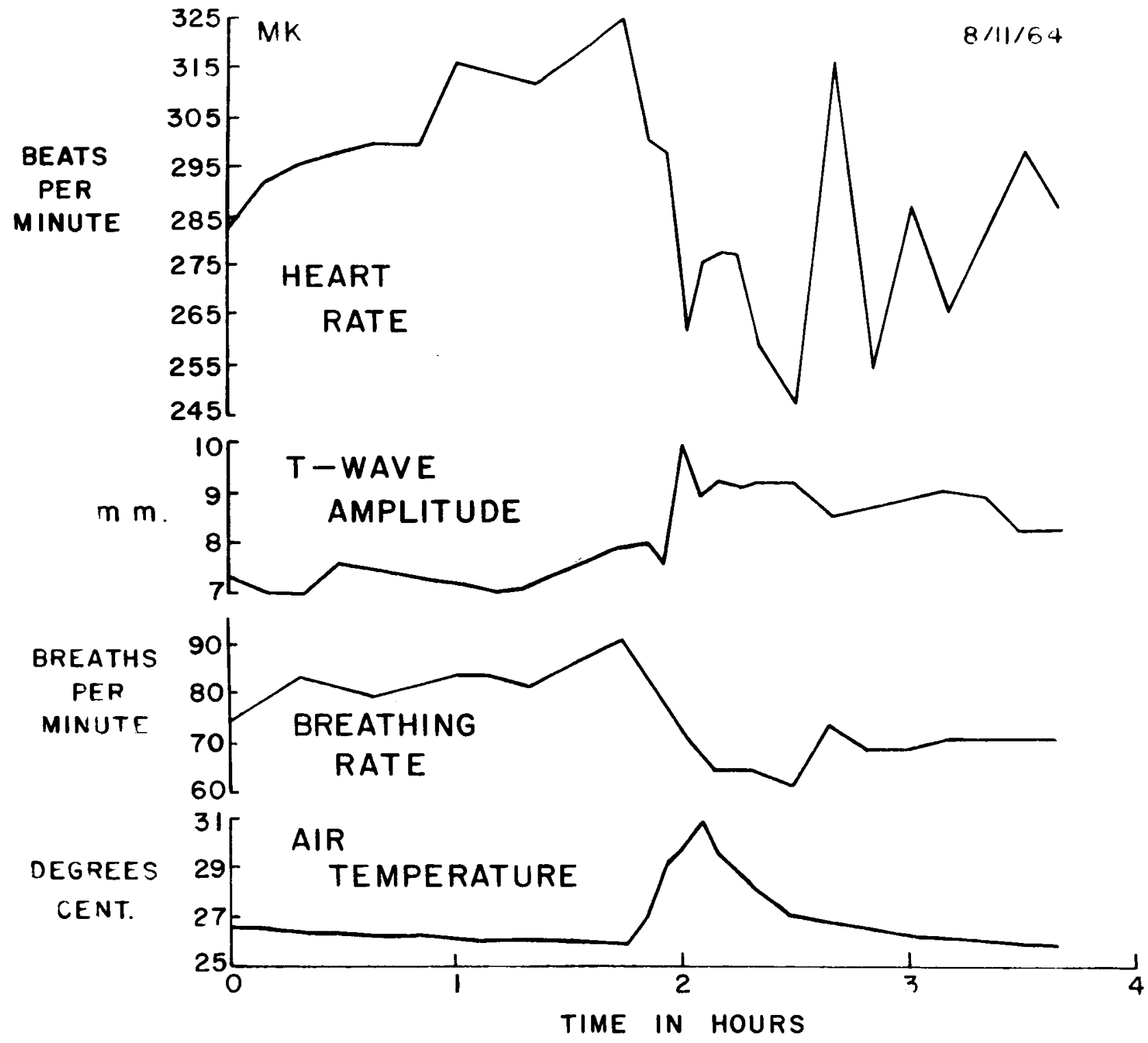

Figure 2

Effects of $5^{\circ} \mathrm{C}$ Temperature Increase in 17-minutes on Several Parameters in Monkey MK. 


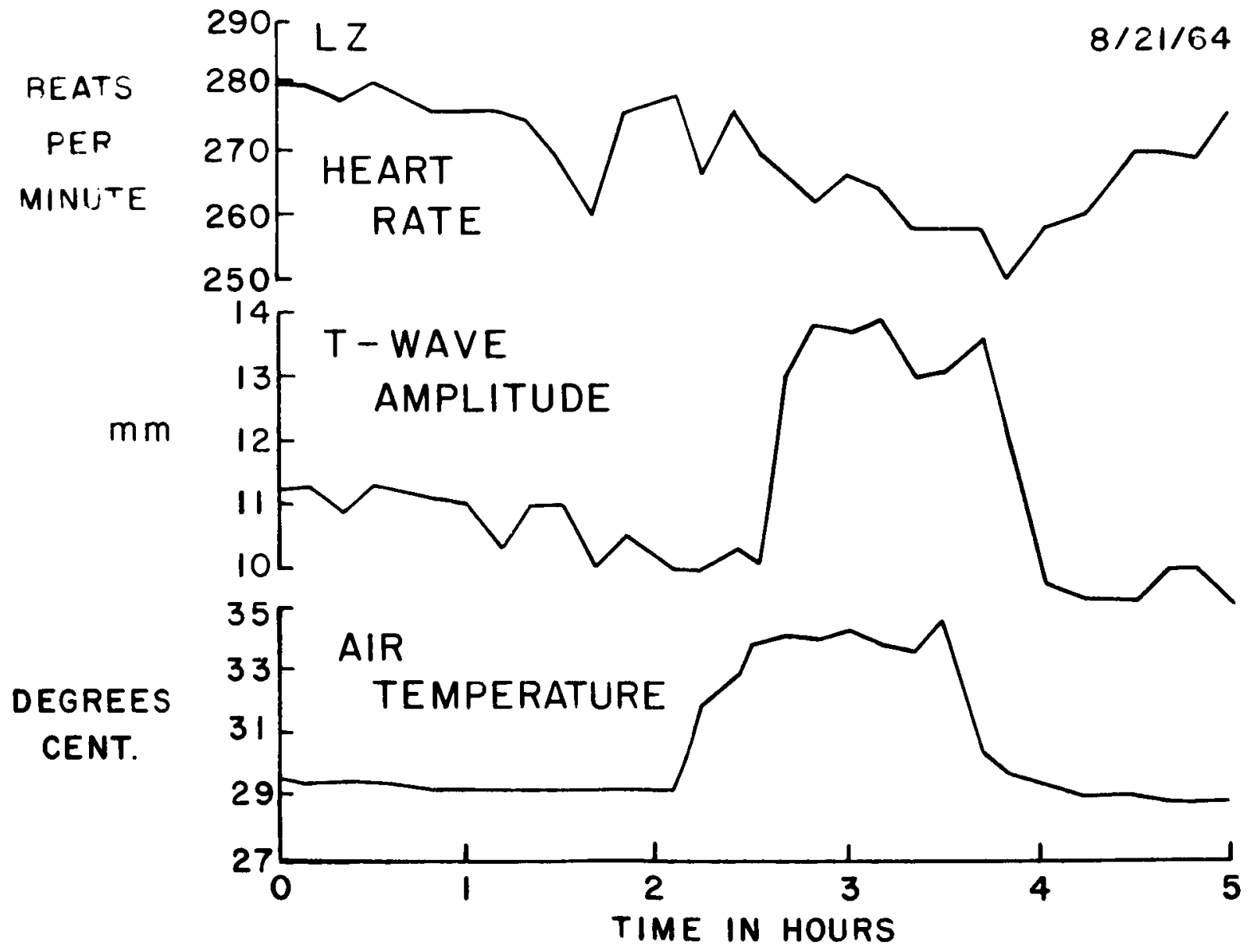

Figure 3

Effects of $5^{\circ} \mathrm{C}$ Temperature Increase Maintained for One Hour on Heart Rate and T-wave Amplitude in Monkey LZ. 


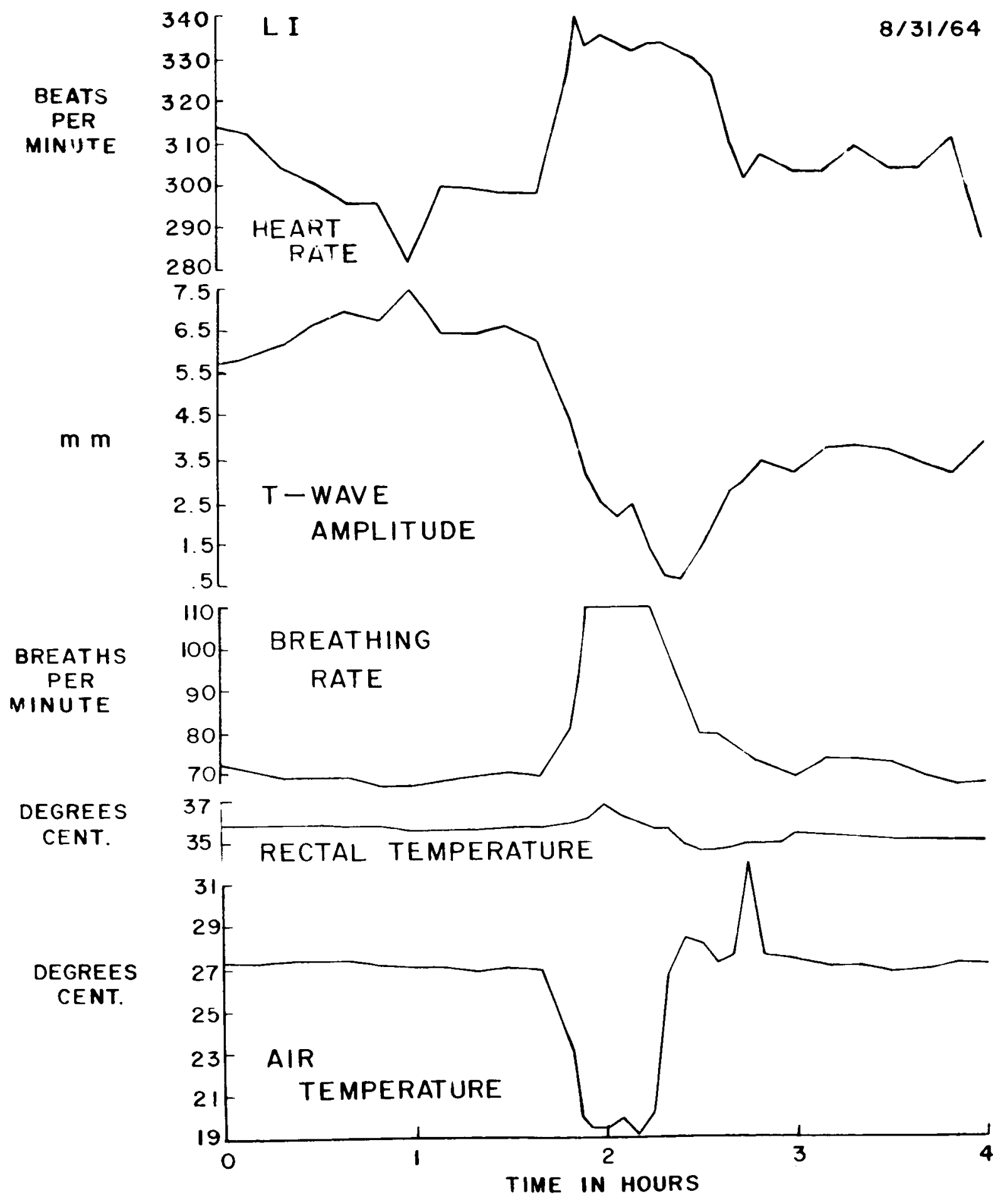

Figure 4

Effects of $8^{\circ}$ Temperature Decrease on Several Parameters in Monkey LI. Test Was Conducted Five Weeks After the Increased Temperature Session Shown in Figure 1. 


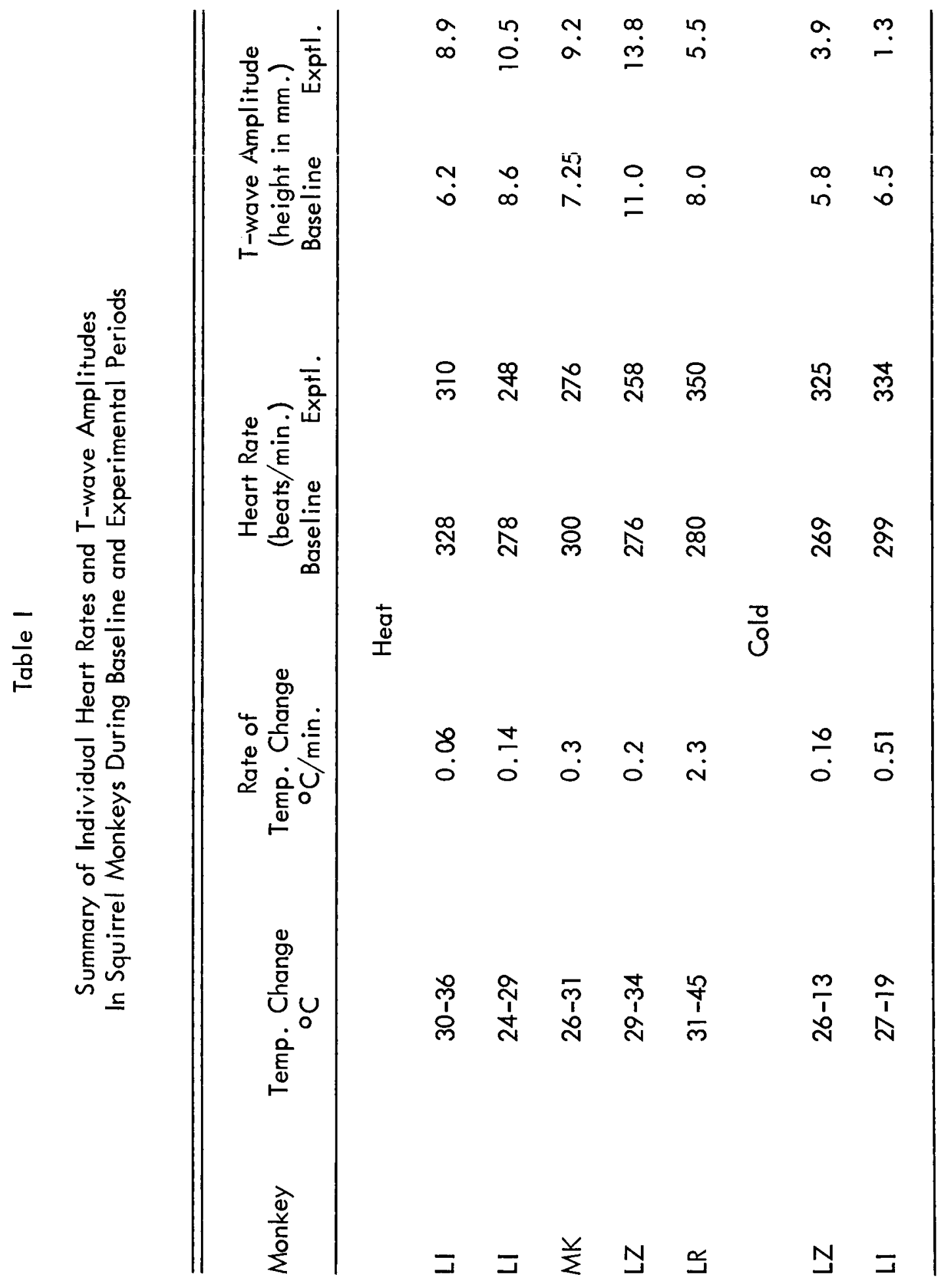


were compared with the three to five values obtained during the trial period. The heart rate changes during heating or cooling were all highly significant, ranging from $p<.02$ to $p<.002$ on the two-tail " $U$ " test. The changes in T-wave amplitude were similarly evaluated. The difference between baseline and experimental values was again highly significant, ranging from $p<.01$ to $p<.001$ on the two-tail test.

Data clearly indicate (Table I) that a decrease in ambient temperature produced a greatly increased heart rate and decreased amplitude of T-wave while a rise in environmental temperature caused a decrease in heart rate and an increase in T-wave amplitude. As the rate of temperature change increased, the latency period for T-wave and heart rate modifications became more apparent.

Table I further demonstrates that an unusually rapid and extreme rise in air temperature produced very different effects. To examine the latency of heart rate change to a fast temperature rise, a $14^{\circ} \mathrm{C}$ change was used at a rate of $2.3^{\circ} \mathrm{C} /$ minute. In this trial the animal exhibited a greatly increased heart rate and reduced $T$-wave amplitude. Although air temperature declined after reaching $45^{\circ} \mathrm{C}$, the heart rate continued to accelerate to 420 and 440 beats/minute.*

\section{DISCUSSION}

In this study unanesthetized squirrel monkeys capable of maintaining normal body temperature exhibited cardiac responses to small heat loads characterized by a decelerated heart rate and increased $T$-wave amplitude. This finding is at variance with the cardiac response of humans who, though maintaining a constant body temperature upon exposure to environmental heating, show significant increases in heart rate $(7,9,12)$. It is possible that a similar response would be found in humans as in monkeys but that it was overlooked because of its transitory nature and limited response range. Other sources for this discrepancy could be in species variations, or in any of a number of procedural factors such as amount, rate, and duration of environmental heating. Since response of one monkey exposed to a rapid and moderately sized environmental temperature increase agrees with the human response, procedural factors appear crucial in clarifying the extent of species differences. Since rectal temperature remained constant, surface temperature receptors appear to mediate heart rate changes. The onset of heart rate changes frequently occurred after an ambient temperature rise of only $2^{\circ}-3^{\circ} \mathrm{C}$, indicating the sensitivity of these temperature receptors. The significance of these sensitive receptors was demonstrated by the death of a monkey exposed to a rapid temperature change. Evidently, squirrel monkeys are not able to tolerate under these conditions the moderate changes in environmental temperature which many humans undergo daily.

*The monkey was removed from restraint at this point but went into shock and died several hours later. 
Our findings on intact monkeys who maintain normal body temperatures are also in contrast with heart rate data obtained in studies which produce a hypo-or hyperthermic state. For example, in an extensive study of the response of mammalian hearts to temperature, Adolph (1) found that heart rate was essentially a linear function of body temperature. Using Capuchin and Spider monkeys as subjects, Wilber $(15,16)$ recently reported data on EKG values during hypothermia resulting from anesthesia. As in Adolph's study, heart rate decreased as the temperature of the body declined. In humans, heart rate reportedly increased by about 10.5 beats/minute for each $1^{\circ} \mathrm{F}$ increase in body temperature (14). Isolated heart preparations show a similar direct relationship to temperature with a $Q$ usually much greater than one.

A change in heart rate is considered a reliable index of the relative activity of the two divisions of the autonomic nervous system (11). Accordingly, the decrease in heart rate found in squirrel monkeys during exposure to warm air might reflect increased parasympathetic tone and/or decreased sympathetic activity (4). An animal can respond to increased heat loads either by increasing its heat loss, or decreasing its heat production, or both. While redistribution of the blood to the surface is a frequent mechanism for increasing the loss of body heat, the occurrence of peripheral vasodilation usually causes a drop in blood pressure. In accordance with Marey's law (4), a decreased blood pressure should lead to an increased heart rate. As evidenced by the reverse response of the squirrel monkey to heat, either other physiological factors are overriding the blood pressure/heart rate relationship or peripheral vasodilation is not occurring. The stability of skin temperature recorded in one monkey (LI, Figure 1) suggests that, under these mild conditions, body heat is not being dissipated through vasodilation. Another explanation for our findings could be related to the fact that the heart is a major heat producing organ in the body. Deceleration of the heart then would reduce the production of body heat as a counterbalance to imposed heat loads from outside.

Our finding that heart rate accelerates during exposure to cold agrees with studies on cats $(6)$ and humans $(5,10)$. The increased heart rate presumably reflects the heightened activity of the sympathetic nervous system with concomitant peripheral vasoconstriction and shivering.

Throughout all trials an inverse relationship between heart rate and T-wave amplitude was observed. A similar correlation between circulation and $T$-wave amplitude was found in an investigation of the factors influencing the T-wave of the EKG in humans (13). The suggestion that parasympathetic activation is associated with an augmented T-wave (11) agrees with our data.

It is not entirely surprising that a direct correlation between heart and breathing rates was typically observed. But heart rate change was not controlled by breathing rate since, in one trial, the heart rate declined with no detectable change in respiration. It is of interest that the breathing rate like the heart rate showed a decline during heating rather than the expected increase. This indicates that the squirrel monkey was not using panting To reduce his temperature. 
It is unlikely that our results are attributable to factors other than temperature. Fluctuations in room noise were masked by the use of a continuous "white" noise throughout each trial. The monkey was visually isolated from us. Adequate ventilation precluded asphyxia as a factor during heating. The data on two animals exposed to both heat and cold demonstrate that the cardiac response was contingent on the direction of temperature change and that excitement during exposure was not a factor.

In view of the increased use of the squirrel monkey as an experimental animal and the unusual nature of its response to environmental temperature changes, it would be of interest to extend these observations. It is clear that in future experiments involving the EKG of the squirrel monkey the environmental temperature must be controlled very closely. 


\section{REFERENCES}

1. Adolph, E. F., Some differences in responses to low temperature between warmblooded and cold-blooded vertebrates. Amer. J. Physiol., 166: 92-103, 1951.

2. Beischer, D. E., and Furry, D.E., Saimiri sciureus as an experimental animal. Anat. Record, 148: 615-624, 1964.

3. Beischer, D.E., and Knepton, J.C., Jr., Influence of strong magnetic fields on the electrocardiogram of squirrel monkeys (Saimiri sciureus). Aerospace Med., 35: 939-944, 1964.

4. Best, C.H., and Taylor, N.B., The Physiological Basis of Medical Practice. 5th ed. Baltimore: Williams and Wilkins, 1950.

5. Brooks, C. McC., et al., Excitability of the Heart. New York: Grune and Stratton, 1955.

6. Cannon, W.B., The Wisdom of the Body. New York: W.W. Norton, 1939.

7. Cooper, K.E., and Kerslake, D.McK., Changes in heart rate during exposure of the skin to radiant heat. Clin. Sci., 14: 125-135, 1955.

8. Graybiel, A., et al., An account of experiments in which two monkeys were recovered unharmed after ball istic space flight. Aerospace Med., 30: 871-931, 1959.

9. Grollman, A., The Cardiac Output of Man in Health and Disease. Springfield, III.: Charles C Thomas, 1932.

10. Herrington, L.P., The range of physiological response to climatic heat and cold. In: Newburgh, L. (Ed.), Physiology of Heat Regulation and the Science of Clothing. Philadelphia: W. B. Saunders, 1949. Pp $\overline{262}-\overline{276}$.

11. Schaeffer, H., and Haas, H., Electrocardiography. In: Handbook of Physiology. Volume I. Circulation. Washington, D.C.: American PhysiologicaT Society, 1962. Pp 323-415.

12. Schneider, E.D., Physiology of Muscular Activity. Philadelphia: W.B. Saunders, 1941 .

13. Siostrand, T., Experimental variations in the T-wave of the electrocardiogram. Acta Med. Scand., 138: 191-200, 1950.

14. Wakim, K.G., Bodily reactions to high temperature. Anesthesiology, 25: 532-548, 1964. 
15. Wilber, C.G., Response of heart in two new world monkeys to hypothermia. Comp. Biochem. Physiol., 11: 323-327, 1964.

16. Wilber, C.G., Some electrocardiographic values in new world monkeys. Amer. Zool., 2: 458-459, 1962. (Abstract).

17. Winslow, C.-E.A., and Herrington, L.P., Temperature and Human Life. Princeton: Princeton University Press, 1949. 
DOCUMENT CONTROL DATA - R\&D

(Security classification of tItle, body of abstract and indexing annotation must be entered when the overall report is clas sified)

1. ORIGINATING ACTIVITY (Corporato author)

U. S. Naval School of Aviation Medicine

Pensacola, Florida

2a. REPORT SECURITY CLASSIFICATION UNCLASSIFIED

2b. GROUP

3. REPORT TITLE

The Effects of Environmental Temperature Changes on the EKG of the Squirrel

Monkey (Saimiri sciureus)

4. DESCAIPTIVE NOTES (Typo of roport and inclusive dates)

5. AUTHOR(S) (Lat namo, firet namo, initial)

Eskin, Arnold and Riccio, David C.

\begin{tabular}{|c|c|c|}
\hline $\begin{array}{l}\text { 6. REPO RT DATE } \\
12 \text { MaY } 1965 \\
\end{array}$ & $\begin{array}{l}\text { 7a. TOTAL NO. OF PAGES } \\
15\end{array}$ & $\begin{array}{c}\text { 7b. NO. OF REFS } \\
17\end{array}$ \\
\hline $\begin{array}{l}\text { a. CONTRACt OR GRANT No. } \\
\text { NASA Order No. R-39 } \\
\text { b. PROJECT No. MRO05.13-9010 }\end{array}$ & \multicolumn{2}{|c|}{$\begin{array}{l}\text { 9a. ORIGINATOR'S REPORT NUMBER(S) } \\
\text { NSAM } 926\end{array}$} \\
\hline c. & $\begin{array}{c}\text { 9b. OHTHER AEPORT NO(S) } \\
\text { (this report) } \\
2\end{array}$ & other numbers that may bo easiened \\
\hline
\end{tabular}

10. AVAILABILITY/LIMITATION NOTICES

Qualified requesters may obtain copies of this report from DDC. Available, for sale to the public, from the Federal Clearinghouse for Scientific and Technical Information, Springfield, Virginia, 22151.

\begin{tabular}{l|l} 
11. SUPPL EMEN TARY NOTES & 12. SPONSORING MILITARY ACTIVITY
\end{tabular}

13. ABSTRACT

Electrocardiograms of four monkeys were recorded during exposure of the animals to air slowly heated $5^{\circ}-8^{\circ} \mathrm{C}$ above room level. Neither rectal nor skin temperature was affected. Deceleration of the heart and increase in $T$-wave amplitude under these conditions are noteworthy phenomena. As a control, EKG records for two of the monkeys were similarly recorded during exposure to slowly cooling air. Rectal temperature showed a very small change. Heart rate and respiration rate increased and T-wave amplitude decreased considerably. 
Security Classification

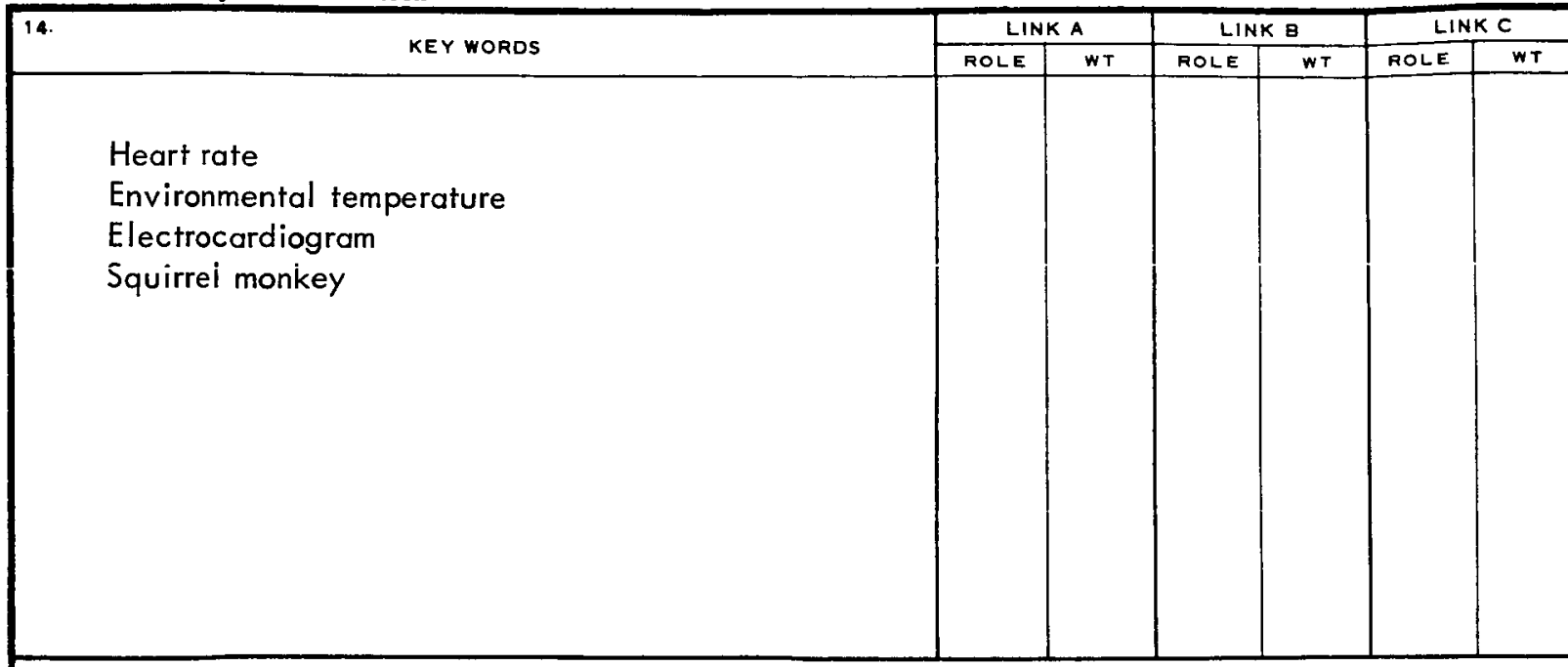

\section{INSTRUCTIONS}

1. ORIGINATING ACTIVITY: Enter the name and address of the contractor, subcontractor, grantee, Department of Defense activity or other organization (corporate author) issuing the report.

2a. REPORT SECURTY CLASSIFICATION: Enter the overall security classification of the report. Indic ate whether "Restricted Data" is included Marking is to be in accordance with appropriate secturity regulations.

2b. GROUP: Automatic downgrading is specified in DoD Directive 5200.10 and Armed Forces Industrial Manual. Enter the group number. Also, when applicable, show that optional markings have been used for Group 3 and Group 4 as authorized.

3. REPORT TITLE: Enter the complete report title in all capital letters. Titles in all cases should be unclassified. If a meaningful title cannot be selected without classification, show title classification in all capitals in parenthesis immediately following the title.

4. DESCRIPTIVE NOTES: If appropriate, enter the type of report, e.g., interim, progress, summary, annual, or final. Give the inclusive dates when a specific reporting period is covered.

5. AUTHOR(S): Enter the name(s) of author(s) as shown on or in the report. Enter last name, fir st name, middle initial. If military, show rank and branch of service. The name of the principal author is an ahsolute minimum requirement.

6. REPORT DATE: Enter the date of the report as day, month, year; or month, year. If more than one date appears on the report, use date of publication.

7a. TOTAL NUMBER OF PAGES: The total page count should follow normal pagination procedures, i.e., enter the number of pages containing information.

7b. NUMBER OF REFERENCES: Enter the total number of references cited in the report.

8a. CONTRACT OR GRANT NUMBER: If appropriate, enter the applicable number of the contract or grant under which the report was written

8b, 8c, \& 8d. PROJECT NUMBER: Enter the appropriate military department identification, such as project number, subproject number, system numbers, task number, etc.

9a. ORIGINATOR'S REPORT NUMBER(S): Enter the official report number by which the document will be ident ified and controlled by the originating activity. This number must be unique to this report.

9b. OTHER REPORT NUMBER(S): If the report has been assigned any other report numbers (either by the originator or by the sponsor), also enter this number(s).

10. AVALABILITY/LIMITATION NOTICES: Enter any $1 \mathrm{im}$ itations on further dissemination of the report, other than those imposed by security classification, using standard statements such as:

(1) "Qualified requesters may obtain copies of this report from DDC."

(2) "Foreign announcement and dissemination of this report by DDC is not authorized."

(3) "U. S. Government agencies may obtain copies of this report directly from DDC. Other qualified DDC users shall request through

(4) "U. S. military agencies may obtain copies of this report directly from DDC. Other qualified users shall request through

(5) "All distribution of this report is controlled. Qualified DDC users shall request through .$\cdots$

If the report has been furnished to the Office of Technical Services, Department of Commerce, for sale to the public, indicate this fact and enter the price, if known.

11. SUPPLEMENTARY NOTES: Use for additional explanatory notes.

12. SPONSORING MILITARY ACTIVITY: Enter the name of the departmental project office or laboratory sponsoring (paying $f o r)$ the research and development. Include address.

13. ABSTRACT: Enter an abstract giving a brief and factual summary of the document indicative of the report, even though it may also appear elsewhere in the body of the technical report. If additional space is required, a continuation sheet shall be attached.

It is highly desirable that the abstract of classified reports be unclassified. Each paragraph of the abstract shall end with an indication of the military security classification of the information in the paragraph, represented as (TS), (S), (C), of (U)

There is no limitation on the length of the abstract. However, the suggested length is from 150 to 225 words.

14. KEY WORDS: Key words are technically meaningful terms or short phrases that characterize a report and may be used as index entries for cataloging the report. Key words must be selected so that no security classification is required. Identifiers, such as equipment model designation, trade name, military project code name, geographic location, may be used as key words but will be followed by an indication of technical context. The assignment of links, roles, and weights is optional. 